Proceedings of SALT 26: 185-204, 2016

\title{
Are all concessive scalar particles the same? Probing into Spanish siquiera*
}

\author{
Luis Alonso-Ovalle \\ McGill University
}

\begin{abstract}
Concessive scalar particles (CSPs) (Crnič 2011a,b) (Slovenian magari, Greek esto, and Spanish siquiera, among others) are focus sensitive polarity items that get licensed in a variety of non-veridical contexts, where they trigger a characteristic interpretation: they convey a strengthening effect in downward entailing environments, a 'settle for less' interpretation in modal contexts, and a negative bias in questions. This paper explores the characterization of this class of items by probing into Spanish siquiera. The paper reveals differences between siquiera and magari that challenge a straightforward extension to siquiera of the analysis of CSPs presented in Crnič 2011a and Crnič 2011b and shows that the analysis of esto in Giannakidou 2007 does not cover siquiera either-partly for reasons already pointed out for magari by Crnič. The central insights of Crnič's and Giannakidou's work are nevertheless reconciled in an alternative analysis. The picture that emerges is that CSPs might all convey an existential meaning that determines a set of alternatives, but differ with respect to the role that these alternatives play in determining their interpretation and distribution.
\end{abstract}

Keywords: concessive scalar particles, even NPIs, negative bias, exhaustification

\section{Introduction}

Crnič (2011a,b) uses the term 'concessive scalar particles' (CSPs) to refer to a class of focus sensitive polarity items that share a superficially similar interpretation. The class includes Greek esto (Giannakidou 2007), Spanish aunque sea (Lahiri 2008, 2010) and siquiera (Herburger 2003; Alonso-Ovalle 2009), and Slovenian magari. ${ }^{1}$ What kind of polarity items are CSPs? Is the class of CSPs uniform? If not, how do CSPs differ from each other? This paper contributes to answering these questions by probing the behavior of Spanish siquiera.

* Thanks to the audiences at CLS 52 and SALT 26, and to Luka Crnič, Anastasia Giannakidou, Oriana Kilbourn-Cerón and Bernhard Schwarz for discussions at various stages of this project. All errors are mine. Funding by FRQSC 2013-NP-164823 and SSHRC 435-2013-0103 is gratefully acknowledged. 1 See Gast \& van der Auwera 2011 for a typology.

(C)2016 Alonso-Ovalle 
The paper shows that there are distributional and interpretational differences between siquiera and magari that challenge a straightforward extension to siquiera of the analysis of CSPs presented in Crnič 2011a and Crnič 2011b. The analysis of esto presented in Giannakidou 2007 does not cover siquiera either, mainly for reasons already pointed out for magari by Crnič. Although neither of these analyses extend without modification to siquiera, the paper puts forth an alternative proposal that reconciles some central insights from Crnič's and Giannakidou's work. The analysis retains from Crničc's proposal the idea that CSPs convey a weak existential meaning, and from Giannakidou's the idea that CSPs exclude their scalar alternatives. The picture that emerges is that CSPs might uniformly convey an existential meaning that determines a set of alternatives, but differ with respect to the role that these alternatives play in determining their interpretation and distribution.

The paper is organized as follows: Section 2 describes the behavior of siquiera, Sections 3 and 4 discuss the analysis of CSPs presented in Crnič 2011a and Crnič $2011 \mathrm{~b}$ and the challenges posed by siquiera, Section 5 assesses the extension to siquiera of the analysis of esto presented in Giannakidou 2007, and Section 6 presents an analysis of siquiera that reconciles the two proposals previously discussed.

\section{Siquiera: Distribution and interpretation}

Like other CSPs, siquiera has a restricted distribution. Herburger (2003) described its NPI-like behavior: siquiera is deviant in positive episodic sentences and licensed in downward entailing (DE) environments, as (1), with sentential negation, shows. ${ }^{2,3}$

(1) Pedro (no)* ganó siquiera la medalla de $[\text { bronce }]_{\mathrm{F}} /$ \# de $[\text { oro }]_{\mathrm{F}}$. Pedro not won:3s SIQUIERA the medal of bronze / \# of gold

'Pedro did not even win bronze / \# gold.'

When licensed, CSPs convey a scalar meaning component. The negative version of (1) where siquiera associates with bronze conveys that the bronze medal was the most likely one for Pedro to win, and the version where it associates with gold that it was the gold one - hence its deviance. This meaning component projects like a presupposition: (1) conveys the same scalar component as the sentences in (2).

a. \# ¿Ganó siquiera la de $[\text { oro }]_{\mathrm{F}}$ ?

won:3s SIQUIERA the of gold

b. \# Si ganara siquiera la de [oro $]_{F}$, pasaría a la final.

if won:SUBJ3S SIQUIERA the of gold would-pass to the final

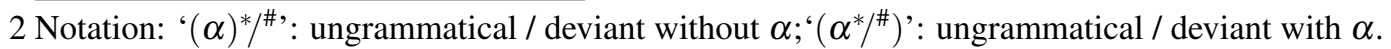

3 The behavior of CSPs in DE contexts differs across languages. Slovenian magari rejects clausemate sentential negation. See Alonso-Ovalle 2009 for a list of DE environments where siquiera is licensed. 
Probing into Spanish Siquiera.

In DE environments, siquiera conveys a strengthening effect. With siquiera, (3) conveys that Pedro did not win a medal, hence the clash with the continuation. ${ }^{4}$

(3) Pedro no ganó (siquiera $^{\#}$ ) la de bronce, pero ganó la de plata. Pedro not won:3s SIQUIERA the of bronze but read:3s the of silver

'Pedro didn't (even") win bronze, but he won silver.'

Like other CSPs, siquiera is also licensed in questions, where it conveys a negative bias. Assuming that the first, second, and third chapters are contextually relevant, the polar question in (4) is incompatible with the speaker suspecting that Pedro read the first chapter and with her suspecting that Pedro read the second or third.

(4) Y Pedro, ¿leyó siquiera el [primer $]_{\mathrm{F}}$ capítulo? and Pedro, read:3S SIQUIERA the first chapter

'And what about Pedro, did he even read the first chapter?'

Finally, siquiera is licensed in modal environments, like magari and esto, as (5), with the necessity modal tener que ('have to'), illustrates. In cases like (5), siquiera conveys a 'settle for less' effect: (5) indicates that the addressee can go more often, but is not required to-going only once is fine with the speaker. ${ }^{5}$

(5) Tienes que ir a la piscina siquiera [una $]_{F}$ vez.

have-to:2s that go to the pool SIQUIERA one time

'You have to go to the pool at least once.'

The challenge that CSPs present is how to derive their restricted distribution together with the characteristic interpretations illustrated above.

Under negation, and in questions, the interpretation of CSPs is reminiscent of that of English even, when this item associates with a low scalar item, as in (6) below: the sentence in (6a) invites the inference that John didn't read any chapters, and (6b) conveys a negative bias, just like their counterparts with siquiera do. The analysis of CSPs presented in Crnič 2011a and Crnič 2011b, to which we turn next, draws on this analogy.

a. John didn't even read the $[\text { first }]_{F}$ chapter.

b. Can he even add $[1 \text { and } 1]_{\mathrm{F}}$ ?

(Guerzoni 2004: 53)

4 This effect corresponds to the 'characteristic implications' of German auch nur (Schwarz 2005).

5 This interpretation corresponds to the so-called 'authoritative reading' of English at least with necessity modals (Büring 2008; Penka 2015; Schwarz 2016; Kennedy 2015). Kadmon \& Landman (1993) use the term 'settle for less' to refer to the interpretation of any under factive emotives and Nakanishi \& Rullmann (2009) to describe the so-called concessive at least. In what follows, I gloss the interpretation of siquiera with either even or at least. This is only an approximation, I don't assume an exact correspondence between the interpretation of these items and siquiera. 
Alonso-Ovalle

\section{The Even plus Weak Associate Analysis (Crnič 2011a,b)}

According to the EVEN plus Weak Associate Analysis (Crnič 2011a,b), CSPs decompose into two focus sensitive propositional operators: EVEN and AT LEAST, as in (7). AT LEAST takes as arguments a contextually determined set of propositions (its domain) - the value of a variable $\mathrm{C}_{n}$ - and a proposition $p$ (its prejacent), it conveys the presupposition that $p$ is the most likely alternative in $\mathbf{C}_{\mathbf{n}}$ and, when this presupposition is met, it weakens $p$ by mapping it to the proposition that $p$ or a less likely alternative in $\mathbf{C}_{\mathbf{n}}$ is true, as in (8a). ${ }^{6}$ EVEN also takes a set of alternatives $\mathbf{C}_{n}$ and a proposition $p$, it triggers the presupposition that $p$ is not the most likely alternative in $\mathbf{C}_{\mathbf{n}}$, and, when the presupposition is met, it returns $p$, as in (8b).

a. * Pedro leyó siquiera el [primer $]_{\mathrm{F}}$ capítulo

b. LF: EVEN $\mathrm{C}_{2}$ AT LEAST $\mathrm{C}_{1}$ [Pedro read the [first $]_{\mathrm{F}}$ chapter]

$$
\begin{aligned}
& \text { a. } \llbracket \mathrm{AT} \mathrm{LEAST}_{\mathrm{C}_{n}} \rrbracket^{c}=\lambda p: \forall q \in \mathbf{C}_{\mathbf{n}}\left[q \neq p \rightarrow q \triangleleft_{c} p\right] . \lambda w . \exists q \in \mathbf{C}_{\mathbf{n}}\left[p \unlhd_{c} q \& q(w)\right] \\
& \text { b. } \llbracket \mathrm{EVEN}_{\mathrm{C}_{n}} \rrbracket^{c}=\lambda p: \exists q \in \mathbf{C}_{\mathbf{n}}\left[p \triangleleft_{c} q\right] . p
\end{aligned}
$$

The analysis exploits the consequences of the correlation between logical strength and probability assignments in (9) below, as in Lahiri 1998.

$$
\text { If } p \subseteq q \text {, then } p \unlhd_{c} q
$$

To illustrate, consider ( $7 \mathrm{~b}$ ). Assume that $\mathbf{C}_{\mathbf{1}}$ is the set containing the propositions that Pedro read the first chapter, that he read the second, and that he read the third $(\{1,2,3\})$. Under this assumption, AT LEAST triggers the presupposition that 1 is the most likely proposition in $\mathbf{C}_{\mathbf{1}}$, and, when this is true, it yields the proposition that Pedro read at least one of the three chapters $([1 \vee 2 \vee 3])$. EVEN requires this proposition to be less likely than at least one other proposition in its domain. The domain of EVEN $\left(\mathbf{C}_{\mathbf{2}}\right)$ is the set $\{[1 \vee 2 \vee 3],[2 \vee 3], 3\}$, which contains the propositions that AT LEAST delivers when substituting first with second or third. ${ }^{7}$ Given (9), the presupposition contributed by EVEN is a pathological one-a presupposition that can never be true-since both [ $2 \vee 3]$ and 3 are stronger than $[1 \vee 2 \vee 3]$. The deviance of (7a) is then captured. And so is the licensing of CSPs in DE environments, because the pathology of the EVEN presupposition gets fixed when

6 The analysis assumes that a context $c$ provides an assignment of (subjective) probabilities to propositions. Following Crnič ' ' $p \unlhd_{c} q$ ' conveys that the probability of $p$ in context $c$ is less than or equal to the probability of $q$, and ' $p \triangleleft_{c} q$ ' that it is less. ' $\mathbf{C}_{\mathbf{n}}$ ' refers to the semantic value of variable $\mathrm{C}_{n}$. The domain of EVEN and AT LEAST must be a subset of the focus semantic value of their sisters. I remain silent about the details of focus association.

7 This is a non-trivial simplification. The focus alternatives of the sister of EVEN are actually partial propositions with mutually exclusive presuppositions. See Crnič 2011 b: fn.8 for a refinement of the semantics of AT LEAST and EVEN that can deliver the required alternatives in the domain of EVEN. 
Probing into Spanish Siquiera.

an operator intervening between EVEN and AT LEAST transforms the problematic entailment relations in $\mathbf{C}_{\mathbf{2}}$, as DE operators do. Consider the case of negation, in (10a). When negation intervenes, the prejacent of EVEN is the strongest proposition in $\mathbf{C}_{\mathbf{2}}$, as (10b) shows, and, as a consequence, the EVEN presupposition, in (10c), does not violate (9). The strengthening effect of CSPs in DE environments is also captured, since the local weakening of AT LEAST results here in global strengthening: (10a) conveys that Pedro did not read any chapter. ${ }^{8}$
a. LF: EVEN $_{C_{2}}$ not AT LEAST $\mathrm{C}_{1}$ [Pedro read the [first $]_{\mathrm{F}}$ chapter]
b. $\mathbf{C}_{2}=\{\neg[1 \vee 2 \vee 3], \neg[2 \vee 3], \neg[3]\}$
c. EVEN pres.: $\left(\neg[1 \vee 2 \vee 3] \triangleleft_{c} \neg[2 \vee 3]\right)$ or $\left(\neg[1 \vee 2 \vee 3] \triangleleft_{c} \neg[3]\right)$

The rescuing role of DE interveners plays a central role in capturing the behavior of CSPs in questions. The analysis appeals here to the derivation of the negative bias of even in questions presented in Guerzoni 2004. The basic idea is that, in questions, a silent operator (whether) can introduce a rescuing negation. Simplifying, we can think of whether as an operator that moves from a position where it has propositional scope, creating a function $f$ of type $\langle\langle s t, s t\rangle, s t\rangle$. In its landing site, whether takes $f$ and yields a question denotation: the set of propositions (corresponding to the possible answers of the question) that results from feeding $f$ with the identity function over propositions and with negation, as in (11). A siquiera question, like (12), is structurally ambiguous. When the trace of whether scopes over EVEN, as in (13a), the resulting question denotation, in (13b), is pathological: since presuppositions project past negation, both possible answers trigger the EVEN presupposition of (7b). When the trace of whether intervenes between EVEN and AT LEAST, as in (14), the resulting question denotation contains the same positive answer as in (13b), which is pathologically undefined. However, the negative answer, which corresponds to the interpretation of (10a), triggers the non-pathological presupposition in (10c). The negative bias stems from the use of a 'defective' question, a question that offers a forced choice, because only one of its answers (the negative) can be used.

(11) $\llbracket$ whether $=\lambda f_{\langle\langle s t, s t\rangle, s t\rangle} \cdot\{f(\lambda p \cdot p), f(\llbracket n o t \rrbracket)\}$

(12) ¿Leyó siquiera el [primer] $]_{\mathrm{F}}$ capítulo?

(13) a. $\mathrm{LF}_{1}$ : whether $\lambda_{1} t_{1\langle s t, s t\rangle}$ EVEN $_{\mathrm{C}_{2}} \mathrm{AT} \mathrm{LEAST}_{\mathrm{C}_{1}}$ [he read the [first $]_{\mathrm{F}}$ chapter] b. $\left\{\begin{array}{c}\llbracket \text { EVEN }_{\mathrm{C}_{2}} \text { AT LEAST } \\ \left.\mathrm{C}_{1} \text { Lhe read the }[\text { first }]_{\mathrm{F}} \text { chapter }\right] \rrbracket^{c}, \\ \llbracket \text { not } \text { EVEN }_{\mathrm{C}_{2}} \text { AT LEAST } \\ \left.\mathrm{C}_{1} \text { [he read the }[\text { first }]_{\mathrm{F}} \text { chapter }\right] \rrbracket^{c}\end{array}\right\}$

$$
\left.\mathrm{LF}_{2} \text { : whether } \lambda_{1} \text { EVEN }_{\mathrm{C}_{2}} t_{1\langle s t, s t\rangle} \text { AT LEAST } \mathrm{C}_{1} \text { [he read the [first }\right]_{\mathrm{F}} \text { chapter] }
$$

8 This derivation of the strengthening effect is proposed for German auch nur in Schwarz 2005. 
The logic that explains the licensing of CSPs in DE environments does not extend to the modal cases, though, because modals preserve the problematic entailment relations in the domain of EVEN. Consider (15): the prejacent of EVEN (the proposition in bold type in (15b)) is the weakest proposition in $\mathbf{C}_{\mathbf{2}}$. Why are modals possible licensers then? The EVEN + Weak Associate Analysis provides an elegant explanation. Sentences containing an existential expression scoping under a modal routinely trigger strengthened interpretations. The sentence in (16a), for instance, is associated with the interpretation in (16bi) (its 'free choice' interpretation), rather than with the expected weaker truth-conditions in (16bii). If the prejacent of EVEN conveys a strengthened free choice interpretation (the proposition in bold type in (17)), it will not be logically related to its alternatives, and, as result, EVEN will not contribute a pathological presupposition.

$$
\text { a. LF: } \left.\text { EVEN }_{\mathrm{C}_{2}} \square \text { AT LEAST } \mathrm{C}_{1} \text { [Pedro read the [first }\right]_{\mathrm{F}} \text { chapter] }
$$

b. $\mathbf{C}_{\mathbf{2}}=\{\square[\mathbf{1} \vee \mathbf{2} \vee \mathbf{3}], \square[2 \vee 3], \square 3\}$

c. EVEN pres.: $\square[1 \vee 2 \vee 3] \triangleleft_{c} \square[2 \vee 3]$ or $\square[1 \vee 2 \vee 3] \triangleleft_{c} \square 3$

a. You have to read chapter one, two, or three.

$$
\begin{aligned}
& \text { b. i. } \square[1 \vee 2 \vee 3] \& \diamond[1] \& \diamond[2] \& \diamond[3] \quad \text { ii. } \square[1 \vee 2 \vee 3] \\
& \mathbf{C}_{\mathbf{2}}=\{\square[\mathbf{1} \vee \mathbf{2} \vee \mathbf{3}] \& \diamond[\mathbf{1}] \& \diamond[\mathbf{2}] \& \diamond[\mathbf{3}], \square[2 \vee 3] \& \diamond[2] \& \diamond[3], \square 3\}
\end{aligned}
$$

The strengthening of the modal prejacent is independently motivated by pointing out that the predicted EVEN presupposition captures the 'settle for less' effect. Suppose that Pedro was more likely to read chapter 1 than 2 or 3 (as AT LEAST requires), because chapter 1 is the easiest and Pedro is lazy. EVEN requires at least one of the alternatives in (17) to be more likely than the prejacent. This will be the case if the speaker is more likely to require Pedro to move beyond his comfort zone and read a chapter that is more difficult than the first. In this context, the speaker was expected to impose a more taxing requirement, but she settled for less.

We conclude here the presentation of the EVEN plus Weak Associate Analysis and turn next to discussing some challenges that siquiera poses for this analysis: the next section probes further into the interpretation and licensing conditions of siquiera and shows that the effects of the EVEN presupposition that are expected under the EVEN plus Weak Associate Analysis are not clearly attested.

\section{Siquiera and the EVEN plus Weak Associate Analysis}

Recall that under the EVEN plus Weak Associate Analysis CSPs are not licensed when the prejacent of EVEN is the weakest alternative in its domain, because, in that case, EVEN triggers a presupposition that can never be satisfied. This happens when no operator intervenes between EVEN and AT LEAST. When the entailments from 
Probing into Spanish Siquiera.

the alternatives to the prejacent of EVEN are reversed (if a DE operator intervenes) or broken (if a modal prejacent gets a strengthened interpretation), EVEN triggers a non-pathological presupposition. In that case, CSPs are predicted to be licensed and the EVEN presupposition is expected to contribute to their interpretation.

In the case of siquiera, the effects of restoring the pathological EVEN presupposition are not the expected ones: entailment reversal can yield a non-pathological EVEN presupposition that rules out siquiera sentences that should not be ruled out, and entailment breaking can deliver a non-pathological EVEN presupposition that does not rule out siquiera sentences that should be ruled out.

Let us focus on entailment reversal first. We noted above that the EVEN plus Weak Associate Analysis correctly captures the interpretation of siquiera with sentential negation. But this is not the best case to test. To see why, consider (10a), repeated as (18a). The sentence corresponding to (18a) presupposes that the first chapter was the most likely one for Pedro to read. The analysis captures this fact, since AT LEAST triggers this very same presupposition, which projects past negation. But what does EVEN contribute? We cannot detect the contribution of EVEN if we look at contexts where the AT LEAST presupposition is met, because whenever the AT LEAST presupposition is true, the EVEN presupposition in (18b) will also be true. ${ }^{9}$ To test the contribution of EVEN, we need to look at other cases of entailment reversal, and, when we do, what we see is that the predicted EVEN presupposition is not attested.

$$
\begin{aligned}
& \text { a. LF: } \left.\text { EVEN }_{C_{2}} \text { not AT LEAST } \mathrm{C}_{1} \text { [Pedro read the [first }\right]_{\mathrm{F}} \text { chapter] } \\
& \text { b. EVEN pres.: }\left(\neg[1 \vee 2 \vee 3] \triangleleft_{c} \neg[2 \vee 3]\right) \text { or }\left(\neg[1 \vee 2 \vee 3] \triangleleft_{c} \neg 3\right)
\end{aligned}
$$

Consider, for instance what happens when siquiera is within the restrictor of a universal quantifier, as in (19a). Because the first argument position of a universal quantifier is a DE environment, scoping EVEN over the universal statement delivers a non-pathological presupposition. In this case, assuming that the AT LEAST presupposition projects universally, the sentence should end up presupposing that every student is more likely to speak once or more than more than once. The EVEN presupposition effectively requires that the proposition that every student who spoke once or more wore yellow trousers be less likely that the proposition that every student who spoke more than once wore yellow trousers. The AT LEAST presupposition seems correct, but (19a) is perfectly fine in cases where the predicted EVEN presupposition is not true. ${ }^{10}$

9 Assume the AT LEAST presupposition is true. Consider (i): $[1 \vee 2 \vee 3] \triangleright_{c}[2 \vee 3]$. For (i) to be false, the probability of [1] would have to be 0 . But then, given the AT LEAST presupposition, the probabilities of [2] and [3] would have to be negative. Since (i) is equivalent to the first disjunct of the EVEN presupposition, if the AT LEAST presupposition is true, the EVEN presupposition must also be true.

10 I assume a non-upper-bounded meaning for una vez. Cases like (19a) are discussed in Schwarz 2000 to argue for the scope theory of even and in Heim 1984 in connection with even NPIs. 
a. Todos los estudiantes que hablaron siquiera [una $]_{F}$ vez llevaban all the students that spoke:3PL SIQUIERA one time wore:3PL pantalones amarillos. trousers yellow

'Every student who spoke at least once wore yellow trousers.'

b. LF: EVEN $_{\mathrm{C}_{3}}$ every [st. $\mathrm{WH}_{1}$ AT LEAST $\mathrm{C}_{2} t_{1}$ spoke [once] $\left.]_{\mathrm{F}}\right][$ wore yellow tr.]

Let us now examine what happens when we break the problematic entailment relations in the domain of EVEN. Consider the case of a non monotone quantifier, like exactly one NP in (20a). When exactly one NP intervenes between EVEN and AT LEAST, as in (20b), the prejacent of EVEN (in bold type in (20c)) is logically independent of its alternatives and, therefore, the predicted EVEN presupposition is not pathological. In the case at hand, assuming, again, universal projection, the AT LEAST presupposition conveys that every athlete is more likely to win bronze than silver or gold. The EVEN presupposition will be satisfied in case the proposition that exactly one athlete wins silver or gold is more likely than the proposition that exactly one athlete wins a medal, and it will also be satisfied if the proposition that exactly one athlete wins gold is taken to be more likely that the proposition that exactly one athlete wins a medal. The predicted EVEN presupposition will be then satisfied in a context where we take it to be very unlikely that only one athlete will win a medal, but we take it to be very likely than only one will win gold. But (20a) remains deviant in this type of context (even when the AT LEAST presupposition is satisfied.) The predicted EVEN presupposition does not rule out siquiera sentences that should be ruled out, then.

$$
\begin{aligned}
& \text { a. \# Exactamente un atleta ganó siquiera la de [bronce }]_{\mathrm{F}} \\
& \text { exactly one athlete won SIQUIERA the of bronze } \\
& \text { b. LF: } \left.\text { EVEN }_{C_{3}} \text { exactly one athlete } \lambda_{1} \text { AT LEAST } \mathrm{C}_{2} t_{1} \text { won [bronze }\right]_{\mathrm{F}} \\
& \text { c. } \mathbf{C}_{\mathbf{3}}=\{\exists ! \mathbf{x}[\mathbf{B}(\mathbf{x}) \vee \mathbf{S}(\mathbf{x}) \vee \mathbf{G}(\mathbf{x})], \exists ! x[S(x) \vee G(x)], \exists ! x[G(x)]\}
\end{aligned}
$$

The behavior of siquiera in modal contexts also casts doubts about the effects of the predicted EVEN presupposition. Recall that siquiera is licensed in modal contexts, which are presumably upward entailing and where we expect in principle a pathological EVEN presupposition. Under the EVEN plus Weak Associate theory, the licensing of CSPs in modal contexts is parasitic on getting a free choice interpretation for the modal prejacent of EVEN, which destroys the problematic entailment relations in the domain of this operator. But in the case of siquiera, this correlation does not seem to be attested. Cases like (21), adapted from Crnič, show a contrast between necessity and possibility modals that we don't find in the case of magari. Although nothing prevents possibility modals from triggering a free choice interpretation, the 
Probing into Spanish Siquiera.

version of (21) with a possibility modal is deviant—even when the predicted EVEN presupposition is met.

(21) Para el pasaporte, Pedro \{ tiene que / \# puede $\}$ enviarme siquiera una for the passport, Pedro \{ has to /\# can $\}$ send-me SIQUIERA a foto $[\text { escaneada }]_{\mathrm{F}}$ photo scanned

'For his passport, Pedro \{ has to / can \} send me at least a scanned photo.' (examples modelled after Crnič 2011a)

In the modal cases where siquiera is licensed, the predicted EVEN presupposition does not seem to be making the expected contribution either. Recall that the EVEN plus Weak Associate Theory derives the 'settle for less' effect of CSPs in modal contexts from the scalar presupposition of EVEN that results from strengthening its modal prejacent. In the case of siquiera, however, this effect is independent of the predicted presupposition of EVEN (Alonso-Ovalle 2009). To illustrate, (22) triggers a 'settle for less' effect: the sentence conveys that the speaker is not requiring the addressee to go to the swimming pool more often than once per week. In (22), EVEN is predicted to convey the presupposition that requiring the addressee to go more often than once a week (and permitting him to go any number of times higher than one) is more likely than requiring him to go once or more (and permitting him to go any times). However, (22) is not deviant in a context where it is taken for granted that the speaker is less likely to require the addressee to go more often than once per week (Alonso-Ovalle 2009).

(22) Tienes que ir siquiera $[u n a]_{F}$ vez por semana a la piscina. have:2s that go SIQUIERA one time per week to the pool

'You have to go at least once per week to the swimming pool.'

The effects of restoring the predicted pathological EVEN presupposition are not clearly attested, then. Do we see the effects of this presupposition when it is predicted to be pathological? The correlation between the pathology of the EVEN presupposition and the licensing of siquiera is not perfect: as (23a) shows, siquiera is licensed in the nuclear scope of universal DPs — an upward entailing environment where siquiera is predicted to convey a pathological EVEN presupposition.

(23) a. Todos los estudiantes hablaron siquiera [una $]_{\mathrm{F}}$ vez. all the students spoke:3PL SIQUIERA one time

'Every student spoke at least once.'

b. LF: EVEN $_{C_{3}}$ every student $\lambda_{1}$ AT LEAST $_{C_{2}} t_{1}$ spoke $[\text { once }]_{\mathrm{F}}$ 
The explanation for the licensing of siquiera in modal environments suggests a possible way to treat cases like (23a): we could assume that siquiera is licensed here by the presence of a covert exhaustification operator that would break the problematic entailment relations in $\mathbf{C}_{\mathbf{3}}$. But there are reasons to be skeptical of that possibility. The LFs below correspond to the two positions where a propositional exhaustification operator could intervene between EVEN and AT LEAST. We can exclude the LF in (24a) because, disregarding its scalar presuppositions, (23a) would be predicted to make the claim that every student spoke exactly once, rather than the attested weaker claim that every student spoke at least once. The LF in (24b) can be excluded on the basis of its predicted EVEN presupposition. Under this representation, (23a) is predicted to presuppose that the proposition that every student spoke at least once and not all spoke more than once is less likely than the proposition that every student spoke more than once. But the sentence is not deviant in a context where students are not expected to speak and where, for instance, it is more likely that all students speak at least once and some only once than that all students speak more than once.

$$
\begin{aligned}
& \text { a. } \left.\operatorname{EVEN}_{C_{4}} \text { every student } \lambda_{1} \operatorname{EXH}_{C_{3}} \text { AT LEAST }_{C_{2}} t_{1} \text { spoke [once }\right]_{\mathrm{F}} \\
& \text { b. } \left.\operatorname{EVEN}_{C_{4}} \operatorname{EXH}_{\mathrm{C}_{3}} \text { every student } \lambda_{1} \text { AT LEAST } \mathrm{C}_{2} t_{1} \text { spoke [once }\right]_{\mathrm{F}}
\end{aligned}
$$

We have then seen that the predicted contribution of EVEN does not fully align with the licensing or interpretation of siquiera in a number of constructions.

To conclude, we will briefly consider the interpretation of siquiera in questions. Under the EVEN plus Weak Associate Analysis, the negative bias of siquiera in (polar) questions is captured by assuming that siquiera questions present the addressee with only one choice: putting forth the negative answer. But siquiera questions are perfectly fine in contexts where the speaker gives her addressee a chance (or even wants her) to give a positive answer-even when the speaker is biased towards the negative answer.

Consider, as illustration, the context in (25) below.

(25) Context: A and B are staying in a hotel during a road trip. Last night, A heard very loud music outside B's room. A suspects that B may not have slept at all, but she wants to know whether B has slept or not, because B is driving and A desperately needs to continue the trip, and if B slept, even if it were only for a very short period of time, they will be fine.

Uttered in the context in (25), the question in (26a), which can be answered positively, as in (26b), is not forcing B to put forth the proposition that he didn't sleep at all. If anything, A wants B to give a positive answer. Rather, the question is requesting whether or not $\mathrm{B}$ has slept, even if it was only for a very short time. ${ }^{11}$

11 The scenario is constructed so that all the speaker wants to know is whether the addressee has slept 
Probing into Spanish Siquiera.

a. A: ¿Dormiste siquiera un poco?

slept:2s SIQUIERA a bit

'Did you sleep at least a bit?'

b. B: Sí. No te preocupes, estoy bien. Podemos seguir.

'Yes. Don't worry, I am fine. We can continue.'

There are then reasons to have doubts about the expected contribution of EVEN to the interpretation or distribution of siquiera. But if EVEN is not responsible for the interpretation or distribution of siquiera, what is? The analysis of Greek esto in Giannakidou 2007 suggests an alternative, to which we turn next.

\section{The Exclusion of Scalar Alternatives Analysis (Giannakidou 2007)}

Under the analysis presented in Giannakidou 2007, esto has no effect on the at-issue content, but conveys two presuppositions: (i) that the associate of esto ranks lower than its alternatives in a contextually determined scale (not necessarily based on likelihood), and (ii) a negative additive presupposition that excludes scalar alternatives (it requires that at least one of them be false). The analysis aims to derive the interpretation of esto in modal contexts and in questions from the negative additive presupposition, arguably avoiding some of the challenges previously discussed.

Consider, for instance, (27a), with esto under an imperative operator. In (27a) esto combines with a set of individuals (its domain) and, as Gianakidou proposes, with an expression of type $e$ (its associate) and a property. ${ }^{12}$ Let us assume that $\mathrm{C}_{\mathbf{1}\langle\mathbf{e}, \mathbf{t}\rangle}$ contains the first, second, and third problems. The sentence in (27a) is predicted to presuppose (i) that the second and third problems rank higher than the first in a contextually determined scale, and (ii) that the addressee did not solve the second or that he did not solve the third. The at-issue content of (27a) conveys that the addressee must solve the first problem. This interpretation is argued to derive a 'settle for less' effect under certain contextual assumptions. Let assume that the contextually relevant scale is one that ranks the problems with respect to how difficult they are for the addressee (with more difficult problems higher in the scale.) The negative additive presupposition will be satisfied in a context where the addressee has not solved problems 2 or 3 . Since these problems are taken to be more difficult for the speaker to solve than problem 1, the speaker is settling for the least taxing requirement. Notice that no claims are being made about the likelihood of the speaker requesting the addressee to solve another problem and that, for this reason,

or not. If the amount of sleep were relevant, a more appropriate positive answer would continue by specifying how much slept the addressee got.

12 As in Giannakidou 2007, we assume that esto has narrow scope over other propositional operators. I adapt slightly the analysis, which does not use a variable to determine the domain of esto. 
the analysis avoids the issue for the EVEN plus Weak Associate Analysis discussed in Section 4 in connection with example (22).

$$
\text { a. } \mathrm{Na} \text { lisis esto to provlima } 1 .
$$
SUBJ solve:2SG EVEN the problem 1

'(Please) solve \{ even / at least $\}$ problem 1.' (Giannakidou 2007: 72)

b. LF: $\square\left[\right.$ [esto $_{\mathrm{C}_{1\langle e, t\rangle}}$ [the first problem]] $\lambda_{1}$ you solve $\left.t_{1}\right]$

c. Scal. pres.: $\forall x \in \mathbf{C}_{\mathbf{1}\langle\mathbf{e}, \mathbf{t}\rangle}\left[x \neq 1\right.$ st problem $\rightarrow\left[1\right.$ st problem $\left.\left.<_{\text {difficulty }} x\right]\right]$

Neg. add. pres.: $\neg$ [you solve the 2 nd] $\vee \neg$ [you solve the 3 rd]

Assertion: $\square$ [you solve the 1st]

Let us turn now to questions. Consider (28). The current analysis does not treat (28) as a defective question. Like its counterpart without esto, (28) is an information seeking question, asking whether the addressee has solved problem 1 or not. Unlike its counterpart without esto, (28) conveys an extreme negative bias towards at least one of the scalar alternatives: the question presupposes that the addressee has not solved at least one of problems 2 and 3. Extending this analysis to siquiera would capture the observation that siquiera questions do not seem to present the addressee with only one choice. But the counterpart of (28) with siquiera conveys that the speaker suspects that the addressee has probably not read chapter 1, a meaning component that the negative additive presupposition does not capture on its own. For the negative bias of siquiera to be derived, something else needs to be said. In a brief remark, Giannakidou 2007 seems to appeal to the following pragmatic reasoning. Suppose that we want to know which problems the addressee has solved. In a context where the scalar presupposition of esto is satisfied and where, for instance, it is taken for granted that the addressee has not solved problem 3, a negative answer to (28) would be more useful for the speaker than a positive answer. We can assume that the easiest problem is the most likely one for the addressee to solve. Learning that the addressee has not solved the most likely problem for her to solve can invite the inference that she has not solved any of the others; but learning that the addressee has solved problem 1 is not very informative and does not give us a clue as to whether she has also solved problem 2 or not. The speaker risks getting a not very useful answer because she suspects that the negative answer is true.

Elises esto to provlima 1? solved ESTO the problem 1

'Did you even solve problem 1?' (Giannakidou 2007: 76)

Although the Exclusion of Scalar Alternatives analysis allows for a characterization of the interpretation of siquiera in modal contexts and in questions that differs 
Probing into Spanish Siquiera.

from that of the EVEN plus Weak Associate analysis, the particular implementation presented in Giannakidou 2007 is not free of challenges. Crnič 2011a presents two: one for the predicted at-issue content, and the other for the predicted negative additive presupposition. First, as Crnič points out for magari, the predicted at-issue content in the modal cases is too strong: (29), for instance, is predicted to convey that the addressee wins bronze in all permitted worlds. If the addressee is not permitted to win more than one medal, (29) should also convey that she cannot win silver or gold. But (29) is compatible with the addressee being allowed to win silver or gold even if she is only permitted to win one medal. ${ }^{13}$

(29) Tienes que ganar siquiera la de [bronce $]_{\mathrm{F}}$. have-to:2s that win SIQUIERA the of bronze

'You have to win at least the bronze medal.'

Let us now consider the predicted negative additive presupposition. Notice that a stronger version of this presupposition would derive the strengthening effect of cases like (30), with sentential negation. If siquiera triggered the presupposition that Pedro didn't read the second or third chapters, and, like esto, were interpreted under negation, as in (30b), the presuppositions and at-issue content of (30) would convey, together, that Pedro did not read any chapters. But just as the EVEN plus Weak Associate Analysis predicts a scalar presupposition that is sometimes unattested, Crnič 2011a,b points out that the Exclusion of Alternatives Analysis predicts an unattested negative additive presupposition in other DE contexts: the sentence in (31), for instance, is appropriate in a context where it is not taken for granted that Pedro didn't speak more than a bit.

a. No leyó siquiera el [primer] $]_{F}$ capítulo. not read:3S SIQUIERA the first chapter

'He didn't even read the first chapter.'

b. LF: not [ [ siquiera $_{\mathrm{C}_{1\langle e, t\rangle}}\left[\right.$ the first chapter] ] $\lambda_{1}$ pro $\left._{2} \operatorname{read} t_{1}\right]$

(31) Si Pedro habló siquiera un poco, le aprobarán. if Pedro spoke:3s SIQUIERA a bit to-him pass:FUT3PL

'If Pedro spoke at least a bit, they will pass him.'

Although the implementation of the analysis presented in Giannakidou 2007 runs into challenges, we will see next its central idea-the exclusion of scalar competitors - can provide the basis for an alternative analysis of siquiera, once it is reconciled with a central component of the EVEN plus Weak Associate Analysis: that CSPs convey existential quantification over their scalar alternatives.

13 This is also a problem for the analysis presented in Alonso-Ovalle 2009. 
Alonso-Ovalle

\section{The AT LEAST plus Exclusion of Alternatives Analysis}

We will conclude the paper by sketching an alternative analysis of siquiera. The analysis adopts from the Exclusion of Scalar Alternatives Analysis the idea that CSPs exclude alternatives, and retains from the EVEN plus Weak Associate Analysis two claims: (i) that CSPs convey that the scalar alternative determined by their associate is the most likely one, and (ii) their existential semantics. The analysis departs from the Exclusion of Scalar Alternatives Analysis in the type of alternatives that get excluded and the assumption that they get excluded via a presupposition.

\subsection{Ingredients}

We will adopt Crnič's AT LEAST operator, but will work within a two-tier system that computes ordinary meanings $\left(\llbracket \cdot \rrbracket^{\mathrm{o}}\right)$ and alternatives $\left(\llbracket \cdot \rrbracket^{\text {alt }}\right)$ in tandem (Rooth 1985; Krifka 1995; Chierchia 2013). The ordinary meaning of AT LEAST is as before. At the alternative tier AT LEAST introduces two alternatives: that the most likely alternative $p$ is true and no other alternative is ('only $p$ '), and that at least one of the alternatives to $p$ is true ('more than $p$ '), as in (32) — in line with Büring (2008) (and others) for English at least. These alternatives can 'grow' past the point where they are introduced, via pointwise functional application, as (33) illustrates. ${ }^{14}$

$$
\begin{aligned}
& \llbracket \operatorname{AT~LEAST}_{\mathrm{C}_{n}} \rrbracket^{\text {alt }}(p)=\left\{\begin{array}{c}
\lambda w \cdot p(w) \& \neg \exists q \in \mathbf{C}_{\mathbf{n}}[q \neq p \& q(w)], \\
\lambda w \cdot \exists q \in \mathbf{C}_{\mathbf{n}}[q \neq p \& q(w)]
\end{array}\right\} \\
& \square(\mathbf{1} \vee \mathbf{2} \vee \mathbf{3}):\{\square(\text { only } 1), \square(2 \vee 3)\} \\
& \mathbf{1} \vee \mathbf{2} \vee \mathbf{3}:\{\text { only } 1,2 \vee 3\} \\
& \text { AT } \overline{\operatorname{LEAST}}_{\mathrm{C}_{1}} \\
& \text { Pedro read the }[\text { first }]_{F} \text { chapter }
\end{aligned}
$$

At the topmost level, the alternatives introduced by AT LEAST are excluded to optimize the speech act made. In the case of assertions, the alternatives are claimed to be false when they are stronger than the ordinary meaning (and would, therefore, make more informative assertions). This requirement will be implemented as follows: we will assume that the alternatives are used up by a strengthening operator $\mathbb{O}$, which combines with a propositional constituent $\phi$ and conjoins $\llbracket \phi \rrbracket^{\mathrm{o}}$ with the negation of each of the stronger alternatives in $\llbracket \phi \rrbracket^{\text {alt }}$ (if any): ${ }^{15}$

$$
\text { (Preliminary) } \llbracket \mathbb{O}[\phi] \rrbracket^{\mathrm{o}}=\lambda w . \llbracket \phi \rrbracket^{\mathrm{o}}(w) \& \forall q \in \llbracket \phi \rrbracket^{\text {alt }}\left[q \subset \llbracket \phi \rrbracket^{\mathrm{o}} \rightarrow \neg q(w)\right]
$$

14 The nodes dominating AT LEAST and the higher operators are decorated with their ordinary meanings (in boldface type) and their alternatives, separated by a colon. I assume that AT LEAST introduces its presupposition at the ordinary meaning tier and not at the alternative tier (cf. fn. 7)

15 This is, in essence, Krifka's Scal.Assert operator (Krifka 1995: 245). See also Chierchia 2013. 
Probing into Spanish Siquiera.

\subsection{Predictions}

This setup can exploit the logic familiar from the literature on English at least $n$ (Büring 2008; Schwarz 2016). The tree on the left in (35) shows that the alternatives that (1) operates over are symmetric (Schwarz 2016): the ordinary meaning that (1) combines with (in boldface type) entails that one of them is true, and, so, they cannot be both excluded. Assuming that $\mathbb{O}$ can strengthen meanings up to deriving a contradiction (like the strengthening operators in Chierchia 2013), this operator derives a contradiction here. The situation is different if a downward entailing (DE) operator or a necessity modal intervenes between $\mathbb{O}$ and AT LEAST. When a DE operator intervenes, as in the tree on the right in (35), (O) disregards the alternatives, since they are weaker than the ordinary meaning of its argument. When a necessity modal intervenes, it breaks the symmetry of the alternatives: the ordinary meaning at the top of (33) does not entail the disjunction of the alternatives and, therefore, both of them can be excluded. In this case, $\mathbb{O}$ does not derive a contradiction, but rather a strengthened meaning that conveys a 'settle for less' component: the addressee does not have to read the second or third chapters (but she can) and she does not have to read only the first (but she can).

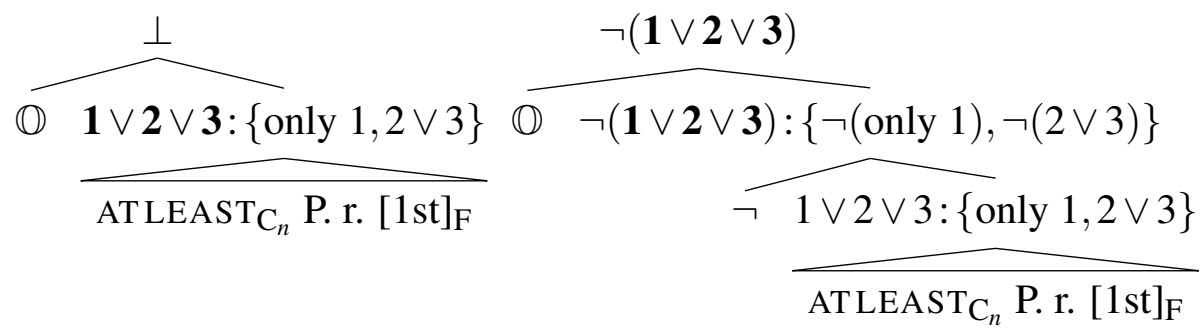

Some of the challenges that the EVEN plus Weak Associate Analysis runs into are now avoided. First, because quantificational DPs with universal force also break the symmetry of the alternatives, we expect siquiera to be licensed in their nuclear scope, as in (23a), repeated below as (36). Assuming that una vez has a non-upper bounded meaning, that una vez contrasts with dos veces ('twice or more'), and universal projection of the AT LEAST presupposition, (36) is predicted to presuppose that each student was more likely to speak once or more than to speak twice or more, and to convey that all students spoke once or more, some spoke only once and some spoke twice or more, which seems correct. ${ }^{16}$

a. Todos los estudiantes hablaron siquiera $[\mathrm{una}]_{\mathrm{F}}$ vez. all the students spoke:3PL SIQUIERA one time

'Every student spoke at least once.'

b. LF: (O) every student $\lambda_{2}$ AT LEAST $\left.\mathrm{C}_{1}\left[t_{2} \text { spoke [once }\right]_{\mathrm{F}}\right]$

16 If $\lambda_{2}$ yields $\{\lambda x . \lambda w . x$ spoke only once at $w, \lambda x . \lambda w . x$ spoke twice or more at $w\}$ as alternatives. 
Second, licensing siquiera in modal contexts is no longer parasitic on getting a free choice interpretation. In fact, because possibility modals preserve the symmetry of the alternatives that AT LEAST introduces, when they intervene between $\mathbb{O}$ and AT LEAST, $\mathbb{O}$ yields a contradiction, deriving the contrast between necessity and possibility modals in (21) above.

Third, since there is no EVEN, the analysis obviously avoids the problems related to postulating a wide scope low likelihood presupposition. As in the Exclusion of Scalar Alternative Analysis, the predicted interpretation for the modal sentence in (29) does not convey that the speaker is more likely to request reading the second or third chapters. As for (19a), repeated below as (37a), assuming, again, that the AT LEAST presupposition projects universally and that once contrasts with twice, (37a) is predicted to presuppose that every student was more likely to speak once or more than twice or more, and, when this presupposition is met, because the alternatives are weaker than the ordinary meaning, (37a) should convey that every student who spoke once or more wore yellow trousers, in accordance with intuitions. ${ }^{17}$

a. Todos los estudiantes que hablaron siquiera [una $]_{\mathrm{F}}$ vez llevaban all the students that spoke:3PL SIQUIERA one time wore:3PL pantalones amarillos. trousers yellow

'Every student who spoke (once or more) wore yellow trousers.'

b. LF: (O) every [ st. $\mathrm{WH}_{1}$ AT LEAST $\mathrm{C}_{1} t_{1}$ spoke [once $\left.]_{\mathrm{F}}\right][$ wore yellow trousers]

The present version of the analysis does not capture the deviance of cases where a non-monotone operator intervenes between $\mathbb{O}$ and AT LEAST, as in (20a) above. To capture these cases, we will assume that $\mathbb{O}$ requires, via a presupposition, that the alternatives be logically related to the ordinary meaning, as in (38) below. ${ }^{18}$

a. Where $\llbracket \phi \rrbracket^{\mathrm{o}} \in D_{\langle s, t\rangle}, \llbracket \mathbb{O}[\phi] \rrbracket^{\mathrm{o}}$ is defined iff $\forall q \in \llbracket \phi \rrbracket^{\text {alt }}\left[q \subseteq \llbracket \phi \rrbracket^{\mathrm{o}} \vee \llbracket \phi \rrbracket^{\mathrm{o}} \subseteq q\right]$

b. When defined, $\llbracket \mathbb{O}[\phi] \rrbracket^{\mathrm{o}}=\lambda w \cdot \llbracket \phi \rrbracket^{\mathrm{o}}(w) \& \forall q \in \llbracket \phi \rrbracket^{\text {alt }}\left[q \subset \llbracket \phi \rrbracket^{\mathrm{o}} \rightarrow \neg q(w)\right]$

What about questions? The current setup allows for a natural extension that would capture the effect of siquiera in questions by assuming, as Giannakidou (2007) proposed for esto, that in this environment siquiera also signals the exclusion of alternatives. For reasons of space, we will simply sketch a possible approach. Following the analysis of alternative-inducing NPIs in questions presented in Krifka 1991 and Krifka 1995, we will assume that, in questions, the alternatives introduced by AT LEAST combine pointwise with a question forming operator (in (39)) and

17 If $\mathrm{wH}_{1}$ yields $\{\lambda x . \lambda w . x$ spoke exactly once at $w, \lambda x . \lambda w . x$ spoke twice or more at $w\}$ as alternatives. 18 Krifka's Scal.Assert also requires the alternatives to be related by informativity. 
Probing into Spanish Siquiera.

determine alternative question denotations. To illustrate, consider again (26a), repeated in (40a). Assuming that a bit contrasts with more than a bit, at the ordinary meaning tier, AT LEAST would yield a partial proposition. This proposition would be defined in case the addressee is more likely to sleep a bit or more than more than a bit, ${ }^{19}$ and, when defined, it would convey that the addressee slept a bit or more than a bit. Combining this partial proposition with ?yes/no we get, at the ordinary meaning tier, the question denotation in (41a). Combining the AT LEAST alternatives with $?$ yes/no, we get the alternative question denotations in $(41 \mathrm{~b}) .{ }^{20}$

$$
\begin{aligned}
& \llbracket ?_{\text {yes/no }} \rrbracket=\lambda p \cdot\{p, \neg p\} \\
& \text { a. ¿Dormiste siquiera } \quad \text { [un poco }]_{\mathrm{F}} \text { ? } \\
& \text { slept } \quad \text { SIQUIERA a bit } \\
& \text { b. LF: } \left.\mathbb{O}_{\mathrm{Q}} \text { ? yes/no AT LEAST } \mathrm{C}_{1} \text { you slept [a bit }\right]_{\mathrm{F}} \\
& \text { a. } \llbracket(40 b) \rrbracket^{\mathrm{o}}=\left\{\begin{array}{c}
\text { you slept a bit or more, } \\
\neg(\text { you slept a bit or more })
\end{array}\right\} \\
& \text { b. } \llbracket(40 b) \rrbracket^{\text {alt }}=\left\{\left\{\begin{array}{c}
\text { you slept only a bit }, \\
\neg(\text { you slept only a bit })
\end{array}\right\},\left\{\begin{array}{c}
\text { you slept more than a bit, } \\
\neg(\text { you slept more than a bit })
\end{array}\right)\right\}
\end{aligned}
$$

By analogy with the case of declaratives, we will assume that the alternative questions introduced by AT LEAST are also being excluded, as in the alternativebased approach to NPIs presented in Krifka 1991 and Krifka 1995. In parallel to the case of declarative sentences, we could propose, as in (40b), that a topmost operator $\mathbb{O}_{\mathrm{Q}}$ ? yes/no makes use of the alternatives introduced by AT LEAST: $\mathbb{O}_{\mathrm{Q}}$ ? yes/no asks the question in the ordinary meaning tier and conveys the reason for the exclusion of the question denotations in the alternative tier. What would the reason for the exclusion of the alternatives be? Simplifying a bit, van Rooy (2003) proposes that the presence of an NPI in an information seeking question signals that the alternative competing questions that the NPI determines are more biased, i.e. less balanced-that there is more of a difference between the likelihood of their possible answers (Krifka 2003; van Rooy 2003). ${ }^{21}$

The advantage of this setup is that it allows for the characterization of the interpretation of siquiera questions without having to assume that they are defective questions. Consider (40a). $\mathbb{Q}_{\text {? yes/no }}$ would require that both of the questions in (41b) be less balanced than the more general question in (41a). In a perfectly balanced polar question, the (subjective) likelihood of its possible answers is the same (0.5).

19 Assuming a non-upper-bounded meaning for un poco.

20 For perspicuity, (41a) does not represent the AT LEAST presupposition. Recall that the alternatives are not partial propositions.

21 van Rooy (2003) makes a distinction between information-seeking questions and rethorical questions. Krifka (2003) shows that the de-biasing approach naturally extends to rethorical questions too. 
For an alternative question to be less balanced than the ordinary meaning question, the speaker would have to be biased towards one of their possible answers-the (subjective) likelihood of one of their answers would have to be greater than 0.5. Given the logical relation between the propositions in the ordinary meaning question denotation and the propositions in the alternative question denotations, for that to be the case, it would have to be the case that, for each of the alternative questions, the speaker is biased towards the negative answer. For suppose that one of the alternative questions is biased towards the positive answer: for instance, suppose that the probability that the addressee has slept only a bit is 0.6 . For the question in (41a) to be more balanced, the probability of its positive answer would have to be lower than 0.6. But this cannot be the case, because the proposition that the addressee has slept only a bit is stronger than the proposition that the addressee has slept only a bit or more.

What do we get, then? Consider again the scenario in (25). By uttering (40a), the speaker is asking whether the addressee has slept a bit or more or not and conveying that, for her, (i) the addressee is more likely not to have slept only a bit than to have slept only a bit, and (ii) that she is also more likely not to have slept more than a bit than to have slept more than a bit. ${ }^{22}$ The speaker suspects that the addressee has not slept, but it is still asking whether the addressee has slept or not. The question is not a defective one, cornering the addressee to assert that she has not slept, and, therefore, it can still be used by a speaker hoping for a positive answer, as in the scenario in (25).

\section{To conclude}

This paper has probed into siquiera in order to ultimately contribute to the characterization of the class of CSPs. The discussion focused on two analyses of CSPs: the Even plus Weak Associate Analysis (Crnič 2011a,b), which takes Slovenian magari to be representative of the class of CSPs, and the Exclusion of Scalar Alternatives Analysis (Giannakidou 2007), which focuses on Greek esto. We have seen that these analyses do not extend to siquiera, but can be reconciled to characterize this CSP.

If the EVEN plus Weak Associate Analysis proves to be right for magari and the analysis presented here for siquiera, CSPs might uniformly convey an existential meaning that determines a set of alternatives, but differ with respect to the role that these alternatives play in determining their interpretation and distribution-in parallel to what has been argued for other polarity items (see, for instance, Chierchia 2013). Further crosslinguistic research will be useful in assessing this hypothesis.

22 There is also the AT LEAST presupposition, which would effectively convey that the likelihood of the proposition that the addressee has slept only a bit is not zero. 
Probing into Spanish Siquiera.

\section{References}

Alonso-Ovalle, Luis. 2009. Even and biased questions: The case of Spanish siquiera. In Satoshi Ito \& Ed Cormany (eds.), Semantics and Linguistic Theory (SALT) 19, 1-18. Ithaca, NY: Cornell University. doi:10.3765/salt.v1i0.2442.

Büring, Daniel. 2008. The least at least can do. In Charles B. Chang \& Hannah J. Hayne (eds.), West Coast Conference on Formal Linguistics (WCCFL) 26, 114-20. Somerville, MA: Cascadilla Press.

Chierchia, Gennaro. 2013. Logic in Grammar: Polarity, Free Choice and Intervention. Oxford: Oxford University Press. doi:10.1093/acprof:oso/9780199697977.001.0001.

Crnič, Luka. 2011a. Getting 'even'. Cambridge, MA: MIT PhD dissertation.

Crnič, Luka. 2011b. On the meaning and distribution of concessive scalar particles. In Lena Fainleib, Nick LaCara \& Tangsook Park (eds.), North East Linguistic Society (NELS) 41, 143-156. Amherst, MA: GLSA.

Gast, Volker \& Johan van der Auwera. 2011. Scalar additive operators in the languages of Europe. Language 87(1). 2-54. doi:10.1353/lan.2011.0008.

Giannakidou, Anastasia. 2007. The landscape of EVEN. Natural Language and Linguistic Theory 25(1). 39-81. doi:10.1007/s11049-006-9006-5.

Guerzoni, Elena. 2004. Even-NPIs in yes/no questions. Natural Language Semantics 12(4). 319-343. doi:10.1007/s11050-004-8739-0.

Heim, Irene. 1984. A note on negative polarity and downward entailingness. In Charles Jones \& Peter Sells (eds.), North East Linguistic Society (NELS) 14, 98-107. Amherst, MA: GLSA.

Herburger, Elena. 2003. A note on Spanish ni siquiera, even, and the analysis of NPIs. Probus 15(2). 237-256. doi:10.1515/prbs.2003.009.

Kadmon, Nirit \& Fred Landman. 1993. Any. Linguistics and Philosophy 16(4). 353-422. doi:10.1007/bf00985272.

Kennedy, Christopher. 2015. A “de-fregean" semantics (and neo-gricean pragmatics) for modified and unmodified numerals. Semantics and Pragmatics 8(10). 1-44. doi: $10.3765 /$ sp.8.10.

Krifka, Manfred. 1991. Some remarks on polarity items. In Dietmar Zaefferer (ed.), Semantic Universals and Universal Semantics (Groningen-Amsterdam Studies in Semantics 12), 150-189. Berlin: Foris-de Gruyter.

Krifka, Manfred. 1995. The semantics and pragmatics of polarity items. Linguistic Analysis 25. 209-257.

Krifka, Manfred. 2003. Polarity items in questions. Handout of presentation at the Korean Society of Logic and Information, June 28, 2003. http://amor.rz. hu-berlin.de/ h2816i3x/Talks/PolarityQuestionsKorea.ppt.

Lahiri, Utpal. 1998. Focus and negative polarity in Hindi. Natural Language 
Semantics 6(1). 57-123. doi:10.1023/A:1008211808250.

Lahiri, Utpal. 2008. The semantics and pragmatics of some scalar expressions in Spanish. Anuario del Seminario de Filología Vasca Julio de Urquijo 42(2). 359-389.

Lahiri, Utpal. 2010. Some evens are even (if) ... only: The concessive even in Spanish. Ms. JNU, New Delhi.

Nakanishi, Kimiko \& Hotze Rullmann. 2009. More about at least. Handout of a talk presented at The Meeting of Semanticists Active in Canada, May 26, 2009. http://sites.google.com/site/kimikonakanishi/research.

Penka, Doris. 2015. At most at last. In Eva Csipak \& Hedde Zeijlstra (eds.), Sinn und Bedeutung 19, 463-480.

Rooth, Mats. 1985. Association with focus. Amherst, MA: University of Massachusetts at Amherst $\mathrm{PhD}$ dissertation.

van Rooy, Robert. 2003. Negative polarity items in questions: Strength as relevance. Journal of Semantics 20(3). 239-273. doi:10.1093/jos/20.3.239.

Schwarz, Bernhard. 2000. Notes on even. Ms. University of Stuttgart. http: //webpages.mcgill.ca/staff/group4/bschwa8/web/pdf/even.pdf.

Schwarz, Bernhard. 2005. Scalar additive particles in negative contexts. Natural Language Semantics 13(2). 125-168. doi:10.1007/s11050-004-2441-0.

Schwarz, Bernhard. 2016. Consistency preservation in quantity implicature: The case of at least. Semantics and Pragmatics 9. 1-47. doi:10.3765/sp.9.1.

Luis Alonso-Ovalle

Department of Linguistics

1085 Avenue du Docteur Penfield

Montréal, Québec, Canada H3A1A7

luis.alonso-ovalle@mcgill.ca 